\title{
Chlorhexidine for facility-based umbilical cord care: EN-BIRTH multi-country validation study
}

\author{
Sojib Bin Zaman 1*, Abu Bakkar Siddique ${ }^{1}$, Harriet Ruysen², Ashish KC³ ${ }^{3}$ Kimberly Peven², Shafiqul Ameen , \\ Nishant Thakur ${ }^{5}$, Qazi Sadeq-ur Rahman', Nahya Salim ${ }^{6,7}$, Rejina Gurung ${ }^{5}$, Tazeen Tahsina', \\ Ahmed Ehsanur Rahman ${ }^{1}$, Patricia S. Coffey ${ }^{8}$, Barbara Rawlins ${ }^{9}$, Louise T. Day ${ }^{2}$, Joy E. Lawn ${ }^{2 \dagger}$, \\ Shams El Arifeen ${ }^{1 \dagger}$ and EN-BIRTH Study Group
}

\begin{abstract}
Background: Umbilical cord hygiene prevents sepsis, a leading cause of neonatal mortality. The World Health Organization recommends $7.1 \%$ chlorhexidine digluconate (CHX) application to the umbilicus after home birth in high mortality contexts. In Bangladesh and Nepal, national policies recommend CHX use for all facility births. Population-based household surveys include optional questions on CHX use, but indicator validation studies are lacking. The Every Newborn Birth Indicators Research Tracking in Hospitals (EN-BIRTH) was an observational study assessing measurement validity for maternal and newborn indicators. This paper reports results regarding CHX.

Methods: The EN-BIRTH study (July 2017-July 2018) included three public hospitals in Bangladesh and Nepal where CHX cord application is routine. Clinical-observers collected tablet-based, time-stamped data regarding cord care during admission to labour and delivery wards as the gold standard to assess accuracy of women's report at exit survey, and of routine-register data. We calculated validity ratios and individual-level validation metrics; analysed coverage, quality and measurement gaps. We conducted qualitative interviews to assess barriers and enablers to routine register-recording.

Results: Umbilical cord care was observed for 12,379 live births. Observer-assessed CHX coverage was very high at 89.3-99.4\% in all 3 hospitals, although slightly lower after caesarean births in Azimpur (86.8\%), Bangladesh. Exit survey-reported coverage (0.4-45.9\%) underestimated the observed coverage with substantial "don't know" responses (55.5-79.4\%). Survey-reported validity ratios were all poor (0.01 to 0.38). Register-recorded coverage in the specific column in Bangladesh was underestimated by $0.2 \%$ in Kushtia but overestimated by $9.0 \%$ in Azimpur. Register-recorded validity ratios were good (0.9 to 1.1) in Bangladesh, and poor (0.8) in Nepal. The non-specific register column in Pokhara, Nepal substantially underestimated coverage (20.7\%).

(Continued on next page)
\end{abstract}

\footnotetext{
* Correspondence: sojib@icddrb.org

† Joy E Lawn and Shams El Arifeen are joint senior authors.

${ }^{1}$ Maternal and Child Health Division, International Centre for Diarrhoeal

Disease Research, Bangladesh (icddr,b), 68 Shahid Tajuddin Ahmed Sarani,

Mohakhali, Dhaka, Bangladesh

Full list of author information is available at the end of the article
}

(c) The Author(s). 2021 Open Access This article is licensed under a Creative Commons Attribution 4.0 International License, which permits use, sharing, adaptation, distribution and reproduction in any medium or format, as long as you give appropriate credit to the original author(s) and the source, provide a link to the Creative Commons licence, and indicate if changes were made. The images or other third party material in this article are included in the article's Creative Commons licence, unless indicated otherwise in a credit line to the material. If material is not included in the article's Creative Commons licence and your intended use is not permitted by statutory regulation or exceeds the permitted use, you will need to obtain permission directly from the copyright holder. To view a copy of this licence, visit http://creativecommons.org/licenses/by/4.0/ The Creative Commons Public Domain Dedication waiver (http://creativecommons.org/publicdomain/zero/1.0/) applies to the data made available in this article, unless otherwise stated in a credit line to the data. 
(Continued from previous page)

Conclusions: Exit survey-report highly underestimated observed CHX coverage in all three hospitals. Routine register-recorded coverage was closer to observer-assessed coverage than survey reports in all hospitals, including for caesarean births, and was more accurately captured in hospitals with a specific register column. Inclusion of $\mathrm{CHX}$ cord care into registers, and tallied into health management information system platforms, is justified in countries with national policies for facility-based use, but requires implementation research to assess register design and data flow within health information systems.

Keywords: Birth, Newborn, Coverage, Validity, Survey, Hospital records, Health management systems, 7.1\% chlorhexidine, Umbilical cord care, Neonatal sepsis

\section{Key findings}

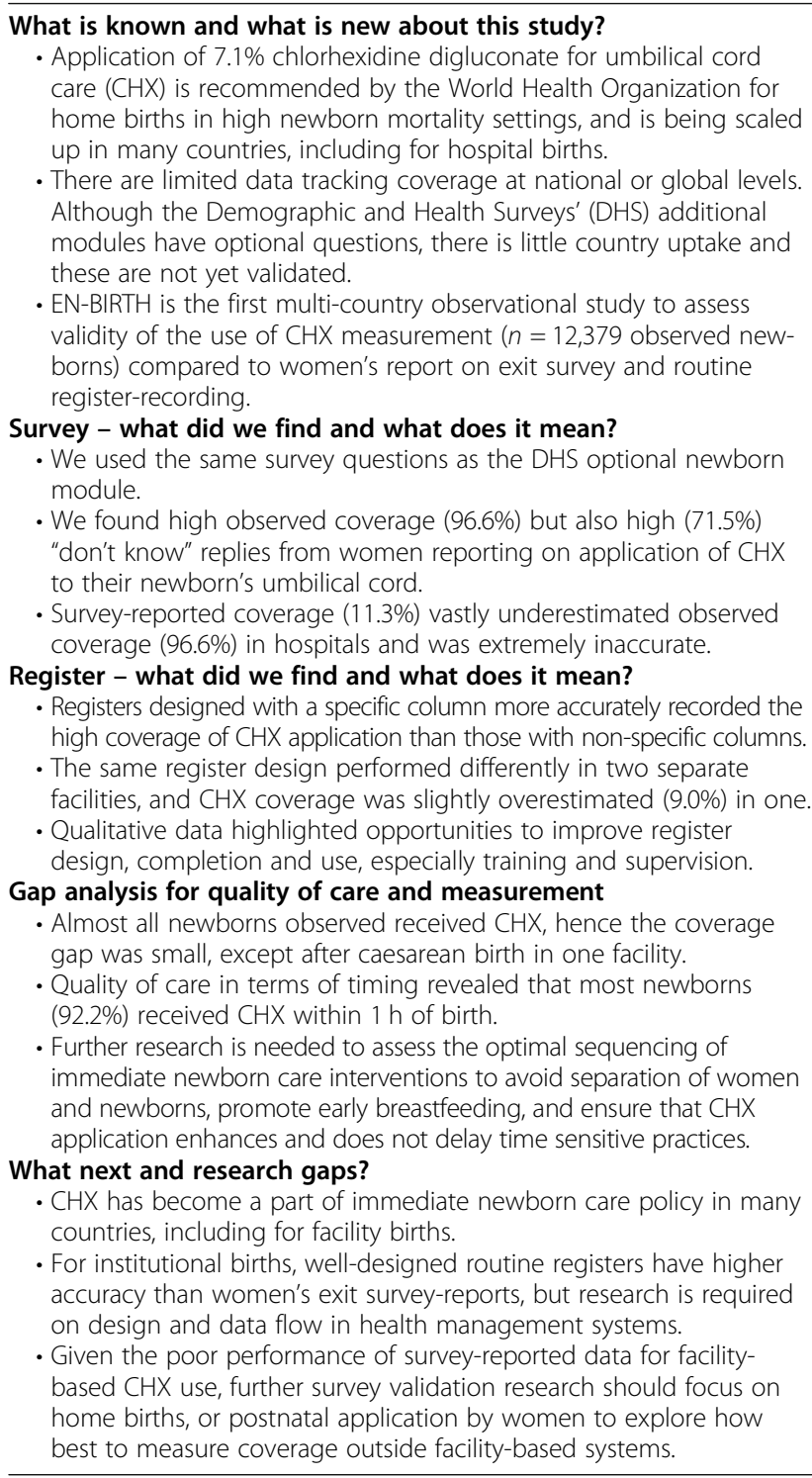

\section{Background}

Globally, almost half of under-five mortality occurs during the first 4 weeks after birth, the neonatal period $[1,2]$.
Infection is a leading cause of neonatal mortality, particularly in high-mortality contexts in low- and middleincome countries $[3,4]$. The newborn umbilical stump is an important entry point for sepsis and systemic infections $[5,6]$. Research has shown that the application of $7.1 \%$ chlorhexidine digluconate (CHX), a broad-spectrum antiseptic, to the umbilical cord can reduce mortality, especially if applied on the first day of life as per World Health Organization (WHO) guidelines [7]. The highest gain is for very low birthweight neonates, where a dose response by birthweight is evident, and newborns benefit from early application [8-10]. Beyond day 1, CHX application reduces the risk of local infection to the cord stump (from 56 to $27 \%$ ) and may also reduce later mortality risk [11]. Hence this low-cost intervention could contribute to reducing the burden of mortality due to neonatal sepsis in the first week of life $[8,12-14]$.

The WHO recommends clean, dry cord care for all newborns and daily CHX application to the umbilical stump for the first week of life for home births in high neonatal mortality settings (> 30 deaths/1000 live births) [6, 15]. These recommendations reflect the evidence available at the time, which included randomised trials mainly conducted in high-mortality home birth settings in south Asia, including Nepal and Bangladesh [6]. These guidelines noted the potential for $\mathrm{CHX}$ application to lower or replace traditional practices, including application of harmful substances such as cow dung [6]. There are now two studies in Africa of umbilical cord cleansing for home births, but these did not report significant mortality benefits [16, 17].

Despite many concerns regarding hospital acquired infections [18, 19], no randomised trial has rigorously assessed mortality effect for facility births to date, although there is an ongoing randomised controlled trial testing a single application of $4 \%$ chlorhexidine in Uganda [20]. Analysis from 3223 facility births in Bangladesh and Nepal observed significant decreases in mortality in newborns who received $\mathrm{CHX}$ [21]. At least 15 countries have implemented a national policy for use of CHX; most, including Bangladesh and Nepal, have a national policy for universal CHX coverage for all births, including those in facilities [22]. 
Tracking coverage of high impact evidence-based interventions is needed to drive progress to achieve Sustainable Development Goal 3.2, ending preventable neonatal mortality. Currently, umbilical cord care coverage is measured by population-based household survey programmes such as the Demographic and Health Surveys (DHS) Program and Multiple Indicator Cluster Surveys (MICS), typically conducted every $2-5$ years (Additional file 1). MICS includes a standard question on cord care practices [23]; however, in DHS this is included in an optional add-on newborn care module with the question: "Was chlorhexidine applied to the stump at any time?" [24] (Additional file 1). Household surveys have many strengths, including a nationally representative sample. However, previous validity research findings for indicators of practices and interventions around the time of birth are mixed. At a minimum, women can only report on clinical interventions they have either discussed with health providers, directly experienced during a state of regular consciousness, or have witnessed [25-30]. Only one previous research study has tested validity of survey CHX measurement in Nigeria, although this had a small sample size [25].

Where CHX application is implemented in facilities, the opportunity exists to track coverage using facility register data for routine health management information systems (HMIS). These data have the advantage of being aggregated and available for use in decision making on a far more frequent basis than household survey data, and thus have the potential to regularly inform quality improvement efforts at subnational levels of the health system. Data accuracy must be trusted to promote use for planning, management, resource allocation and quality monitoring [31]. No previous research has assessed validity of register-recorded measures for CHX coverage [7].

The Every Newborn Action Plan, supported by all United Nations member states and $>80$ development partners, includes an ambitious measurement improvement roadmap $[32,33]$ with an urgent focus on validating indicators for care and outcomes around the time of birth. As part of this roadmap, the Every Newborn- Birth Indicators Research Tracking in Hospitals (EN-BIRTH) study was a mixed-methods observational study of $>23,000$ hospital births in three countries - Bangladesh (BD), Nepal (NP) and Tanzania - and aimed to validate selected newborn and maternal indicators for routine facility-based tracking of coverage, quality of care, and outcomes [34,35]. At the time of study design Tanzania did not have a policy for CHX; therefore, this paper focuses on Bangladesh and Nepal.

\section{Objectives}

This paper is part of a supplement based on the ENBIRTH multi-country validation study, Informing measurement of coverage and quality of maternal and newborn care', and focuses on application of CHX, with three main objectives:

1. Assess NUMERATOR accuracy/validity of measurement for a coverage indicator of single application $7.1 \%$ chlorhexidine to the umbilical cord stump via exit-survey of women's report and routine labour ward register data, compared to observation (gold standard).

2. Analyse GAPS in coverage and quality of care, and measurement for application of $7.1 \% \mathrm{CHX}$ to the umbilical cord stump, including observation data to assess right time, right substance applied and experience of care (assessed via survey-report regarding recall of communication of care).

3. Evaluate BARRIERS AND ENABLERS to routine labour ward register-recording for $\mathrm{CHX}$ through qualitative interviews regarding register design, completion and use.

\section{Methods}

EN-BIRTH was an observational mixed-methods study and compared data from clinical observers about CHX application (gold standard) to women's exit-interview survey reported coverage (Additional file 2) and routine registerrecorded coverage (Fig. 1). Trained health workers observed participants $24 \mathrm{~h}$ per day throughout the woman's admission to labour and delivery ward. They recorded data on care and outcomes, including application of CHX to the umbilical cord stump (Fig. 1). All data collectors were given training to recognise the correct product for local use. Data were collected using a custom-built android tablet-based software application that included timestamps for observation data (July 2017-July 2018) in three public hospitals providing comprehensive emergency obstetric and newborn care (CEmONC) and application of CHX: Maternal and Child Health Training Institute (MCHTI), Azimpur and Kushtia General Hospital in Bangladesh, and Pokhara Academy of Health Sciences in Nepal (Additional file 3). Participants were consenting women admitted in labour in the three study sites (Additional file 4). Metadata definitions for the CHX indicator are also shown (Additional file 1). All statistical analyses were undertaken using Stata 15.0 (Stata Corporation, College Station, TX, USA). Results were reported in accordance with STROBE statement checklists for cross-sectional studies (Additional file 5). Detailed information regarding the research protocol, methods, and analysis has been published separately $[34,35]$.

\section{Labour ward registers}

All three study hospitals used pre-printed routine labour ward registers. The register design in Bangladesh changed to a standardised national labour ward register during the EN-BIRTH study. The revised Bangladesh register 


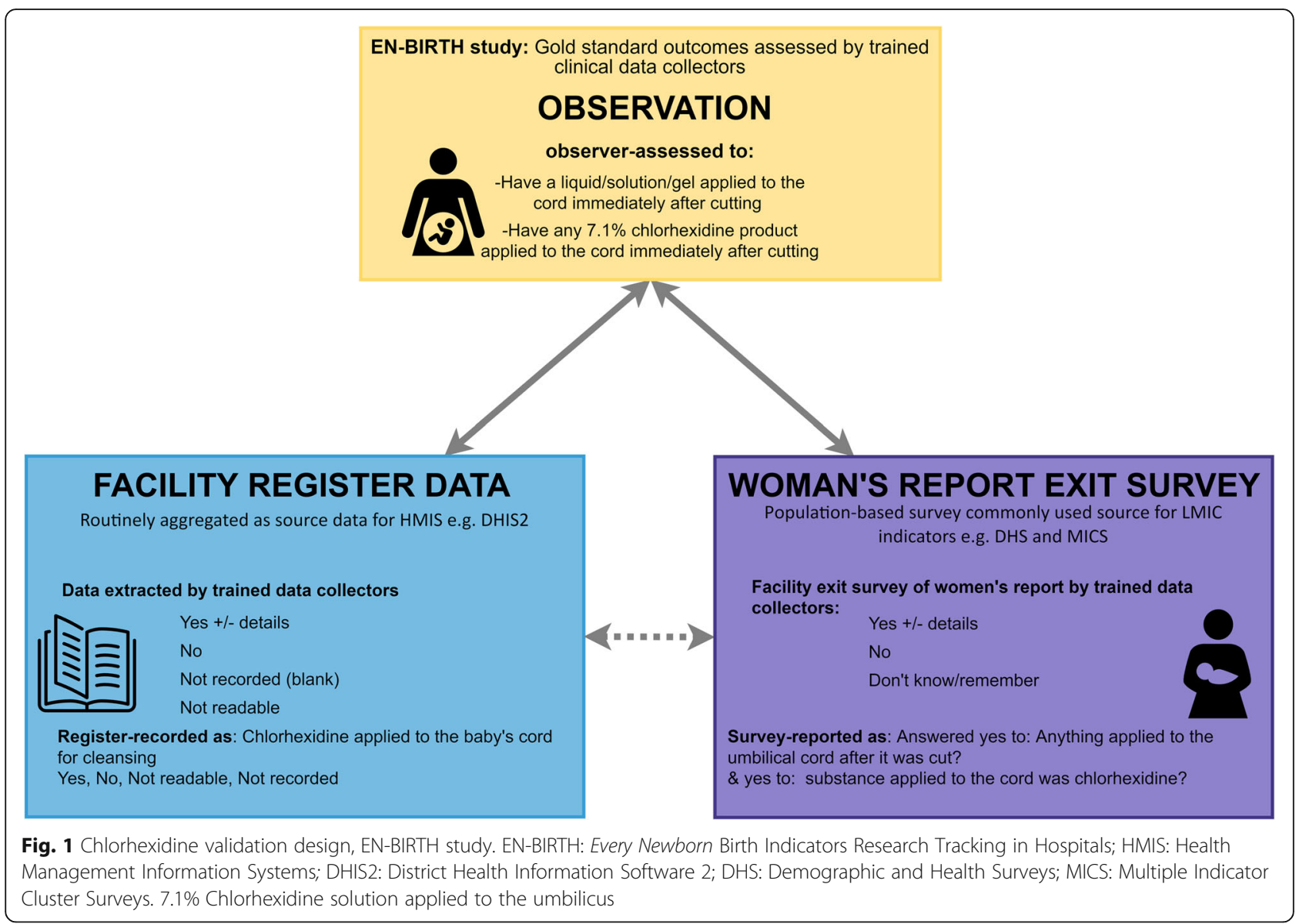

had a new specific column for documenting CHX application labelled, 7.1\% Chlorohexidine used on the umbilical cord. A blank box was provided where staff were instructed to tick for 'given' and leave blank for 'not given'. In Pokhara NP, CHX application was recorded in a nonspecific column labelled "general remarks" and health workers were instructed to document 'CHX is given' or leave blank if 'not given'. Only results from revised registers for the Bangladesh sites are presented in this paper.

\section{Objective 1: Numerator validation}

We compared exit survey-reported and register-recorded coverage to observer-assessed coverage of CHX and stratified by hospital and mode of birth: vaginal births and caesarean births. Percentages of "don't know" replies for exit survey questions, and 'not recorded or not readable' for register-recorded data were also calculated. In line with how DHS/MICS typically analyse 'yes/no/don't know' questions, we compared survey-reported results with "don't know" considered as "no" against "don't know" excluded. Similarly, for register-recorded coverage, we compared results with "not recorded" considered as "no" and also excluded.
We calculated absolute differences between measured coverage (survey or register) and observed coverage of $\mathrm{CHX}$ use to understand under- or over-estimation at the population level. Using two-way tables, we calculated individual-level validity statistics: sensitivity, specificity, and percent agreement ((true positive + true negative)/total) of register-recorded and survey-reported $\mathrm{CHX}$ coverage to observed coverage. Area under the curve, inflation factor, positive predictive value, and negative predictive value were also calculated. We report results where column totals were $>10$ in the two-by-two tables. Pooled results for validity analyses were calculated using random effects metaanalysis, presented with $\mathrm{I}^{2}, \mathrm{\tau}^{2}$, and heterogeneity statistic (Q). We calculated "validity ratios" (against gold standard), heat-mapping results using standard data quality review cut-offs (over/underestimate by $0-5 \%$, by $6-10 \%$, by $11-$ $15 \%$, by $16-20 \%$ and $>20 \%$ ) [36]. All calculations included 95\% confidence intervals (CI) where appropriate.

\section{Objective 2: Gap analysis for coverage and quality of care, and measurement}

We analysed four gaps for CHX use in hospitals: 1) Coverage gap between the target population (all live births) and the observed coverage of CHX. 2) Quality of 
care gap for content - between those newborns observed to have anything applied to the cord and those correctly having CHX applied. Current WHO guidelines suggest CHX application within the first day, however 'correct' time was taken to be within $1 \mathrm{~h}$ of birth, because observations were restricted to the labour and delivery ward in this study. 3) Measurement gap for register records (observed and register-recorded coverage gap). 4) Measurement gap for survey reports (observed and survey-reported coverage of any cord cleansing after birth).

\section{Objective 3: Barriers and enablers to routine recording}

As part of the EN-BIRTH study, qualitative interviews were conducted to understand the barriers and enablers for routine register-recording of interventions around birth. Qualitative data were collected from a purposive sample of health workers (nurses, midwives and doctors) and EN-BIRTH study data collectors. Interviews were recorded, transcribed, translated, and NVivo (QSR International Pty Ltd. Version 12) software was used for data management.

Detailed qualitative methods and overall results are available in an associated paper [37]. Qualitative analysis began with identifying emerging themes based on the Performance of Routine Information System Management (PRISM) conceptual framework [38]. This paper specifically presents themes relating to the recording of umbilical application of CHX.

\section{Results}

\section{Sample description and selection}

Among 12,379 live births observed for CHX use on labour wards in Bangladesh and Nepal, 10,772 live births $(87.0 \%)$ were included for register extraction (Fig. 2). $95.3 \%$ of women completed an exit survey $(12,097$ women interviewed out of the possible 12,692 women observed) which correspond to $95.5 \%$ live births (11,827 live births out of the possible 12,379 live births observed).

Birth outcomes and background characteristics are shown in Table 1. Almost three-quarters (72.8\%) of births in Azimpur BD were via caesarean section compared to $40.3 \%$ in Kushtia BD and $15.5 \%$ in Nepal. Overall, more than $60 \%$ of the women were aged between 20 and 29 years, and $2.7 \%$ were $<18$ years. Completion of secondary education was lowest in Kushtia BD (36.1\%) and highest in Pokhara NP (61.2\%). Approximately $13.4 \%$ of newborns were $<2500$ grammes across the three facilities.

\section{Objective 1: Numerator validation}

To calculate coverage we used the recommend denominator of all live births. In this analyses we included the following denominators: observer-assessed $(n=12,379)$, register-recorded $(n=11,002)$, and exit survey-reported $(\mathrm{n}=11,827)$ live births. Observerassessed coverage of $\mathrm{CHX}$ application within $1 \mathrm{~h}$ of birth was high in all three hospitals for both vaginal births (97.7\%, 95\% CI 94.4-99.6\%) and caesarean sections (97.1\%, 95\% CI 94.4-99.6\%) (Fig. 3).

\section{Exit-interview survey-reported validation}

$\mathrm{CHX}$ coverage was consistently underestimated by survey compared with gold standard in all three sites for vaginal births and caesarean births (Fig. 3). Responses yielded high "don't know" replies for both vaginal births and caesarean section (68.5\%, 95\% CI 47.9-85.9\% / 76.4\%, 95\% CI 66.6-85.0\%, respectively). Percent agreement was low $(18.1 \%, 95 \%$ CI $5.5-35.9 \%)$, and analysis criteria (> 10 column count) was only met for one hospital (Table 2 ). Survey-reported timing of $\mathrm{CHX}$ (within $1 \mathrm{~h}$ of birth) showed high specificity (94.7\% 95\% CI 74.3-100.0\%) but low sensitivity $(6.7 \% 95 \% \mathrm{CI} 0.0-23.9 \%)$ in all hospitals (Additional file 6), including "don't knows". Most women (56.1\% in Kushtia BD to $79.4 \%$ in Pokhara NP) reported that the health worker did not inform them or they did not know if anything was applied to their newborn's umbilical cord (Additional file 7).

\section{Register-recorded validation}

Register-recorded CHX application coverage was variable between the three hospital registers. Most accurate was the register-recorded coverage in Kushtia BD, underestimating by only $0.2 \%$ (Fig 4). This identical register captured CHX in a specific column and overestimated coverage by $9.0 \%$ in Azimpur BD. The least accurate register-recorded coverage was from the non-specific column in Pokhara NP, underestimating coverage by 20.7\%. Register performance to measure CHX application was consistently better for vaginal than caesarean births (Table 3). In Pokhara NP, register-recorded coverage was underestimated by $15.1 \%$ for vaginal births (99.4-84.3\%) and $60.2 \%$ for caesareans (99.2-39.0\%). Percent agreement was high especially for vaginal births (83.9\%) and increased when "don't know" responses were excluded (98.9\%), although all facilities had a column count $<10$ (Additional file 8). In Bangladesh, register instructions dictated that the column was left blank when CHX was not applied, which was problematic for analysis because there was no true measure of 'not given'.

Comparison of heat-mapped validity ratios for exitsurvey or register-recorded measures compared with observer-assessed suggested that register data for CHX was more accurate (ratio 0.94) than women's report (ratio 0.12) Fig 5. It was categorised as 'good' for vaginal births and caesareans (ratios 1.00) in both Bangladesh hospitals. Vaginal births were 'moderate' (ratio 0.85 ) and 


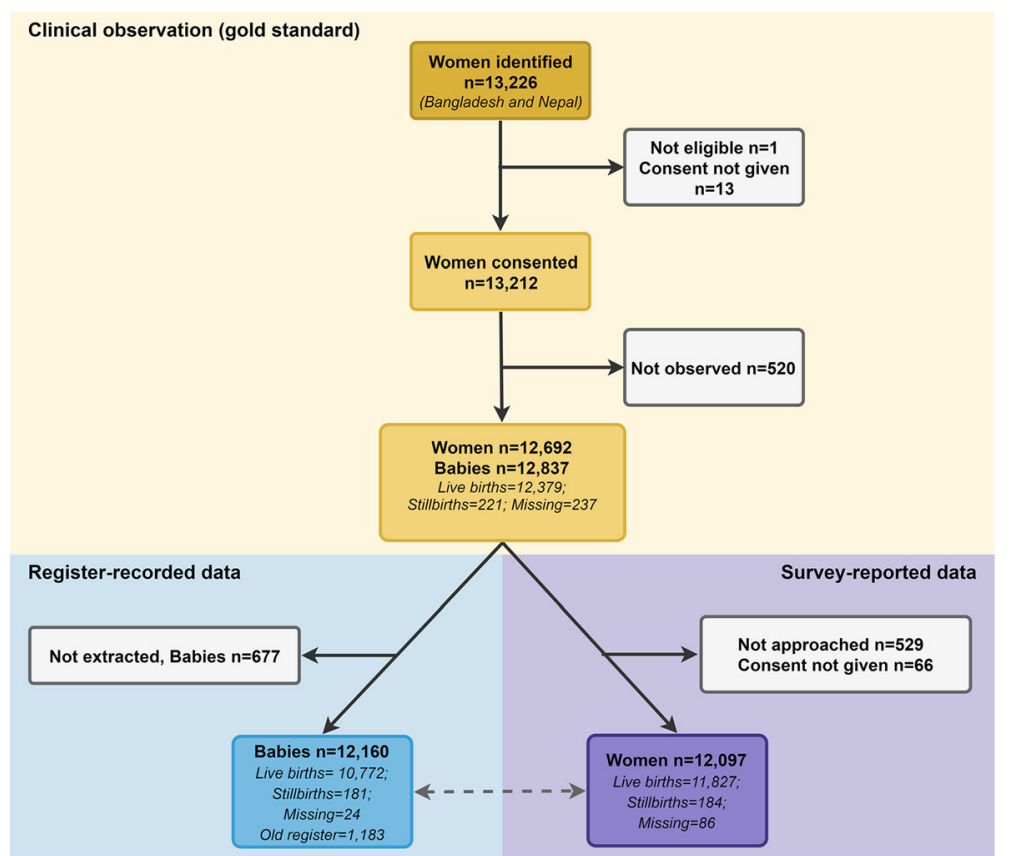

Fig. 2 Flow diagram for cord Chlorhexidine application in Bangladesh and Nepal, EN-BIRTH study. 7.1\% Chlorhexidine solution applied to the umbilicus

caesareans 'poor' (ratio 0.40) in Nepal. Validity ratios for survey-reported results were categorised as 'poor' (ratio range 0.01 to 0.38 ) in all facilities (Fig. 5).

\section{Objective 2: Gap analysis for coverage, quality of care, and measurement}

Almost all newborns in these facilities were observed to receive $\mathrm{CHX}$. The coverage gap was very small for the target population of all live births (Fig. 6). Within these facilities, there was close observed alignment between application of anything and CHX to the cord, however this leads to a measurement gap in survey report where women were more able to report that something was applied (17.8\%), rather than CHX (12.3\%) (Additional file 9). Quality of care gap analysis showed timing distribution (less than $1 \mathrm{~h}$ of birth) was similar among each facility and by mode of birth. Survey reported "don't knows" were higher in Azimpur BD and Pokhara NP considering all modes of birth.

\section{Objective 3: Barriers and enablers to routine recording}

These findings were specific to recording practices for $\mathrm{CHX}$, but more detailed qualitative results are available in a supporting paper [37]. Respondents in all hospitals talked of the complexity of multiple registers (both formal and informal register books) to record interventions around birth, including CHX (Fig. 4).

In Bangladesh the revised register design was an enabler:
"Previously we did not document the care of chlorhexidine in registers as it did not (have) space to write. Now this new register has a specific column where we can document whether chlorhexidine was applied or not."

-Health worker, Azimpur BD

Most respondents from Bangladesh and some in Nepal agreed that it is useful to have a specific column on CHX in the register:

"Now, more information is added to the delivery register than before. For example, information related chlorhexidine was not included before."

-Health worker, Kushtia BD

In Bangladesh, respondents from Kushtia reported that they were not confident to record in the new register due to a lack of formal training. This was in contrast to Azimpur, where more formal supervision and training was provided during the rollout of revised national registers:

"We haven't received any formal training from the hospital. The in-charge has told us verbally how to fill up the register and write information in other informal books."

-Health worker, Azimpur BD 
Table 1 Characteristics of women observed in labour and delivery wards, EN-BIRTH study $(n=12,837)$

\begin{tabular}{|c|c|c|c|c|}
\hline & $\begin{array}{l}\text { Bangladesh } \\
\text { Azimpur Tertiary } \\
\text { n (\%) }\end{array}$ & $\begin{array}{l}\text { Bangladesh } \\
\text { Kushtia District } \\
\text { n (\%) }\end{array}$ & $\begin{array}{l}\text { Nepal } \\
\text { Pokhara Regional } \\
\text { n (\%) }\end{array}$ & All sites \\
\hline A). Total newborns who were observed (Denominator) & 2936 & 2459 & 7442 & 12837 \\
\hline Birth outcome - Live Birth & $2896(98 \cdot 6)$ & 2308 (93.9) & $7175(96 \cdot 4)$ & $12379(96.4)$ \\
\hline \multicolumn{5}{|l|}{ Newborn condition at L\&D discharge } \\
\hline Alive & 2895 (98.6) & $2302(93.6)$ & $7171(96.4)$ & $12368(96.3)$ \\
\hline Stillbirths & $11(0.4)$ & $74(3)$ & $126(1.7)$ & $211(1.6)$ \\
\hline Neonatal death & $1(0)$ & $6(0.2)$ & $4(0.1)$ & $11(0.1)$ \\
\hline Baby not delivered & $2(0.1)$ & $2(0.1)$ & $6(0.1)$ & $10(0.1)$ \\
\hline Birth outcome not observed & $27(0.9)$ & $75(3.1)$ & $135(1.8)$ & $237(1.8)$ \\
\hline \multicolumn{5}{|l|}{ Mode of birth } \\
\hline Normal vaginal birth & $767(26.4)$ & $1364(56.6)$ & $5840(79.2)$ & $7971(62.8)$ \\
\hline Vaginal breech/Vacuum/ Forceps & $1(0)$ & $0(0)$ & $349(4.7)$ & $350(2.8)$ \\
\hline Caesarean Section & $2119(72.8)$ & $972(40.3)$ & $1140(15.5)$ & $4231(33.3)$ \\
\hline Not observed & $23(0.8)$ & $76(3.2)$ & $41(0.6)$ & $140(1.1)$ \\
\hline Birthweight of baby $<2500 \mathrm{~g}$ & $353(11.9)$ & $473(19.3)$ & $897(12.1)$ & $1723(13.4)$ \\
\hline Sex Female/Girl baby & $1427(49)$ & $1128(46.8)$ & $3335(45.3)$ & $5890(46.4)$ \\
\hline B). Total women who were observed & 2910 & 2412 & 7370 & 12692 \\
\hline \multicolumn{5}{|l|}{ Women's Age $^{a}$} \\
\hline$<18$ years & $25(0.9)$ & $3(0.1)$ & $311(4.2)$ & $339(2.7)$ \\
\hline $18-19$ years & $475(16.3)$ & $197(8.2)$ & $817(11.1)$ & $1489(11.7)$ \\
\hline $20-24$ years & $1158(39.8)$ & $954(39.6)$ & $3080(41.8)$ & $5192(40.9)$ \\
\hline $25-29$ years & $867(29.8)$ & $736(30.5)$ & $2114(28.7)$ & $3717(29.3)$ \\
\hline 30-34 years & $297(10.2)$ & $373(15.5)$ & $827(11.2)$ & $1497(11.8)$ \\
\hline $35+$ years & $88(3)$ & $149(6.2)$ & $221(3)$ & $458(3.6)$ \\
\hline Mean (SD) & $23.9(4.5)$ & $24.9(4.9)$ & $24.2(4.7)$ & $24.3(4.7)$ \\
\hline \multicolumn{5}{|l|}{ Women's education $^{a}$} \\
\hline No education & $39(1.3)$ & $77(3.2)$ & $268(3.6)$ & $384(3)$ \\
\hline Primary incomplete & $111(3.8)$ & $127(5.3)$ & $252(3.4)$ & $490(3.9)$ \\
\hline Primary complete & $339(11.6)$ & $347(14.4)$ & $302(4.1)$ & $988(7.8)$ \\
\hline Secondary incomplete & $985(33.8)$ & $954(39.6)$ & $1637(22.2)$ & $3576(28.2)$ \\
\hline Secondary complete or higher & $1273(43.7)$ & $870(36.1)$ & $4509(61.2)$ & $6652(52.4)$ \\
\hline Missing & $163(5.6)$ & $37(1.5)$ & $402(5.5)$ & $602(4.7)$ \\
\hline Mean (SD) & $8.8(4.1)$ & $8.2(3.6)$ & $9.6(4.4)$ & $9.1(4.2)$ \\
\hline
\end{tabular}

${ }^{a}$ Data were collected from women's registration and survey report

\section{Discussion}

EN-BIRTH is the largest observational study to assess validity of coverage measurement for $\mathrm{CHX}$ application through women's exit-interview survey to date, and the first to assess validity of routine hospital registers. Our multi-site, multi-country design enabled comparisons between and within countries. The large sample size enabled the first assessment of how caesarean section affects $\mathrm{CHX}$ coverage measurement.
For household surveys, CHX coverage questions are already included in the optional newborn module of DHS. Our data collectors also showed a visual prompt (a picture of a CHX bottle) to the mother, in line with survey procedures used by DHS for this question. Survey-reported validation results showed substantial underestimation of coverage, especially after caesarean section. "Don't know" responses exceeded 50\% regarding if any substance, or CHX specifically, was applied 


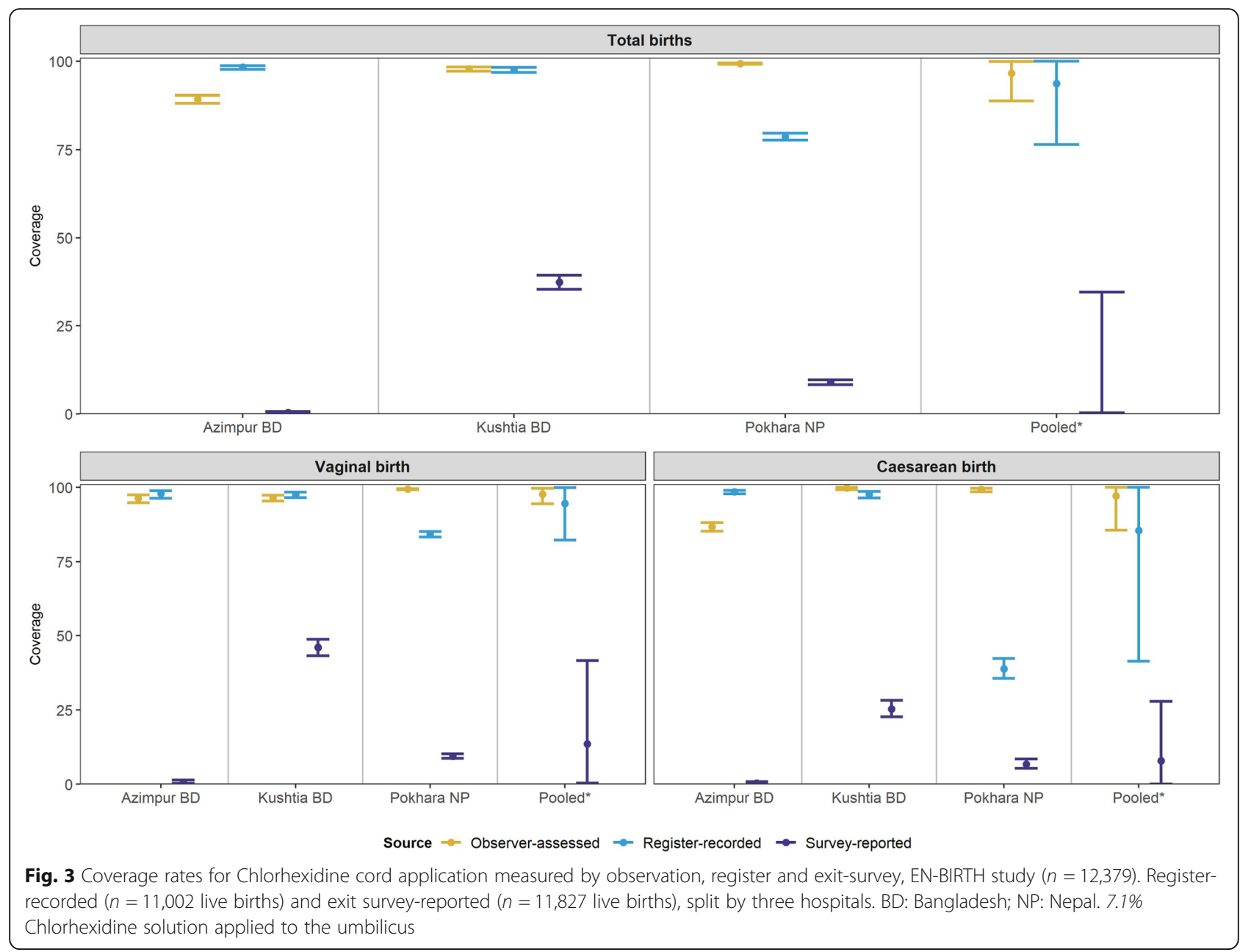

to the cord. These findings are consistent with other research that shows low accuracy of survey-report for clinical interventions around the time of birth [25, 28-30].

A recent study from Nigeria showed much lower "don't know" replies (5\%), and high sensitivity and specificity [25]. Nigeria uses a multi-day regimen in contrast to Bangladesh and Nepal, where a single application is the national standard. In settings using the multiday approach, families are responsible for continuing daily CHX as part of cord care, and it is therefore an imperative that they receive information and training on how to do this. Using our time-stamped data, we learned that $\mathrm{CHX}$ was applied very quickly after birth (median time $2-4 \mathrm{~min}$ ), so it is likely that the mother was not aware of the multi-step process of clamping, tying, cutting the cord, and applying CHX. In the Nigerian study, it is possible that CHX application was outside the immediate postpartum period, perhaps later during the first day (or days after birth). The context of this study was in primary health care facilities, in contrast to our study in busy CEmONC hospitals. Women could have experienced less separation from their newborn and thus been able to see the CHX applied to the cord, or indeed may have had to buy the CHX, or apply it personally. Alternatively, the variation between findings may be associated with the quality of health worker communication to women. Exit survey findings suggest that health worker communication needs improvement. Only $0.1-5.6 \%$ of women reported that health workers told them why $\mathrm{CHX}$ was used. This lack of awareness could be driven by the proximity of events to birth, or a communication failure between health workers and women.

The register data underestimated coverage in two hospitals, performing poorly in one out of three. Register design was found to be an important factor in the accuracy of register-recorded coverage in this study; registers with specific columns outperformed those with nonspecific columns. However, in Bangladesh registers, completion instructions meant it was not possible to understand whether the intervention was deliberately 'not given' or was not recorded in the register for other reasons (i.e. forgotten). Global guidance around register design and indicator prioritisation is required, although implementation and supportive supervision are also crucial. Both hospitals 
Table 2 Individual-level validation in exit survey report of Chlorhexidine cord-application, EN-BIRTH study $(n=6748)$

\begin{tabular}{|c|c|c|c|c|c|c|c|c|}
\hline & \multicolumn{2}{|l|}{$\begin{array}{l}\text { Azimpur (BD) } \\
\text { Tertiary }\end{array}$} & \multicolumn{2}{|l|}{$\begin{array}{l}\text { Kushtia (BD) } \\
\text { District }\end{array}$} & \multicolumn{2}{|l|}{$\begin{array}{l}\text { Pokhara (NP) } \\
\text { Regional }\end{array}$} & \multicolumn{2}{|c|}{$\begin{array}{l}\text { Pooled } \\
\text { (Random effects) }\end{array}$} \\
\hline & $\mathrm{N}(\%)$ & (Cl) & $\mathrm{N}(\%)$ & $(\mathrm{Cl})$ & $\mathrm{N}(\%)$ & $(\mathrm{Cl})$ & N\% & $(\mathrm{Cl})$ \\
\hline Exit-survey denominator & 2826 live births & & 2253 live births & & 6748 live births & & & \\
\hline \multicolumn{9}{|l|}{ All modes of birth combined } \\
\hline Observer prevalence $\%$ & $2582(89.3)$ & & $2257(97.9)$ & & $7112(99.4)$ & & 96.6 & $(88.8,99.9)$ \\
\hline Survey-reported prevalence \% & $12(0.4)$ & & $840(37.3)$ & & $604(9)$ & & $11 . .3$ & $(0.3,34.6)$ \\
\hline Don't know responses \% & $2189(77.5)$ & & $1251(55.5)$ & & $5355(79.4)$ & & 71.5 & $(57.3,83.7)$ \\
\hline \multicolumn{9}{|l|}{ INCLUDES DONT KNOW AS NO } \\
\hline 10 Cell Counts & No & & Yes & & No & & & \\
\hline$\%$ agreement & 11.0 & & 38.4 & & 9.5 & & 18.1 & $(5.5,35.9)$ \\
\hline Sensitivity & $* *$ & $* *$ & 37.7 & $(35.6,39.7)$ & $* *$ & $* *$ & 11.5 & $(0.3,34.9)$ \\
\hline Specificity & ** & ** & 71.7 & $(56.5,84)$ & $* *$ & $* *$ & 93.0 & $(66.0,100.0)$ \\
\hline \multicolumn{9}{|l|}{ EXCLUDES DON'T KNOW } \\
\hline$>10$ Cell Counts & No & & No & & No & & & \\
\hline$\%$ agreement & 11.5 & & 83.7 & & 44.2 & & 45.8 & $(10.0,84.3)$ \\
\hline Sensitivity & 2.1 & $(1.1,3.6)$ & 84.7 & $(82.3,86.9)$ & 44.1 & $(41.4,46.8)$ & 39.7 & $(2.7,86.7)$ \\
\hline Specificity & 100 & $(94.1,100)$ & 23.5 & $(6.8,49.9)$ & 60 & $(14.7,94.7)$ & 70 & $(3.2,100)$ \\
\hline \multicolumn{9}{|l|}{ Vaginal births } \\
\hline Observer prevalence $\%$ & $731(96.3)$ & & $1290(96.5)$ & & 6075 (99.4) & & 97.7 & $(94.4,99.6)$ \\
\hline Survey-reported prevalence \% & $4(0.5)$ & & $601(45.9)$ & & $536(9.3)$ & & 13.6 & $(0.3,41.7)$ \\
\hline Don't know responses \% & $565(76.5)$ & & $629(48.1)$ & & $4508(78.6)$ & & 68.5 & $(47.9,85.9)$ \\
\hline \multicolumn{9}{|l|}{ INCLUDES DONT KNOW AS NO } \\
\hline$>10$ Cell Counts & No & & Yes & & No & & & \\
\hline$\%$ agreement & 4.2 & & 47.8 & & 9.9 & & 17.4 & $(1.6,4.4)$ \\
\hline Sensitivity & $* *$ & $* *$ & 46.9 & $(44.1,49.7)$ & $* *$ & $* *$ & 13.9 & $(0.3,42.5)$ \\
\hline Specificity & $* *$ & $* *$ & 72.7 & $(57.2,85)$ & $* *$ & $* *$ & 91.6 & $(70.3,100.0)$ \\
\hline \multicolumn{9}{|l|}{ EXCLUDES DON'T KNOW } \\
\hline$>10$ Cell Counts & No & & No & & No & & & \\
\hline$\%$ agreement & 5.2 & $(2.4,9.6)$ & 88.2 & $(85.6,90.6)$ & 44.4 & $(41.6,47.3)$ & 44.4 & $(7.5,85.6)$ \\
\hline Sensitivity & 2.4 & $(0.7,6)$ & 89.8 & $(87.2,92)$ & 44.3 & $(41.5,47.2)$ & 42.8 & $(5,86.8)$ \\
\hline Specificity & 100 & $(47.8,100)$ & 25 & $(7.3,52.4)$ & 60 & $(14.7,94.7)$ & 63.2 & $(11.5,100)$ \\
\hline \multicolumn{9}{|l|}{ Caesarean births } \\
\hline Observer prevalence $\%$ & $1850(86.8)$ & & $967(99.8)$ & & $1037(99.2)$ & & 97.1 & $(85.6,100.0)$ \\
\hline Survey-reported prevalence \% & $8(0.4)$ & & $239(25.3)$ & & $66(6.7)$ & & 7.9 & $(0.0,27.9)$ \\
\hline Don't know responses \% & $1624(77.9)$ & & $622(65.9)$ & & $823(83.7)$ & & 76.4 & $(66.6,85.0)$ \\
\hline \multicolumn{9}{|l|}{ INCLUDES DONT KNOW AS NO } \\
\hline$>10$ Cell Counts & No & & No & & No & & & \\
\hline$\%$ agreement & 13.4 & & 25.4 & & 7.1 & & $* *$ & $* *$ \\
\hline Sensitivity & $* *$ & $* *$ & $* *$ & $* *$ & $* *$ & $* *$ & $* *$ & $* *$ \\
\hline Specificity & $* *$ & $* *$ & ** & $* *$ & $* *$ & $* *$ & $* *$ & $* *$ \\
\hline \multicolumn{9}{|l|}{ EXCLUDES DON'T KNOW } \\
\hline$>10$ Cell counts & No & & No & & No & & & \\
\hline$\%$ agreement & 13.9 & $(10.9,17.4)$ & 74.1 & $(69,78.8)$ & 42.3 & $(34,50.8)$ & 42.4 & $(7.4,82.7)$ \\
\hline Sensitivity & 2 & $(0.9,3.9)$ & 74.4 & $(69.2,79.1)$ & 42.3 & $(34,50.8)$ & 34.7 & $(0,88.4)$ \\
\hline Specificity & 100 & $(93.6,100)$ & 0 & $(0,97.5)$ & - & - & 34.7 & $(0,88.4)$ \\
\hline
\end{tabular}

$n=12,379$ observed live births, $n=11,827$ live births with survey

** $=$ result suppressed due to 10 or fewer count per column of two-by-two table

7.1\% Chlorhexidine solution applied to the umbilicus 
Table 3 Individual-level validation of register recording for Chlorhexidine cord-application, EN-BIRTH study $(n=6711)$

\begin{tabular}{|c|c|c|c|c|c|c|c|c|}
\hline & \multicolumn{2}{|l|}{$\begin{array}{l}\text { Azimpur (BD) } \\
\text { Tertiary } \\
\end{array}$} & \multicolumn{2}{|l|}{$\begin{array}{l}\text { Kushtia (BD) } \\
\text { District }\end{array}$} & \multicolumn{2}{|l|}{$\begin{array}{l}\text { Pokhara (NP) } \\
\text { Regional }\end{array}$} & \multicolumn{2}{|c|}{$\begin{array}{l}\text { Pooled } \\
\text { (Random effects) }\end{array}$} \\
\hline & $\mathrm{N}(\%)$ & $(\mathrm{Cl})$ & $\mathrm{N}(\%)$ & $(\mathrm{Cl})$ & $\mathrm{N}(\%)$ & (Cl) & $\mathrm{N}(\%)$ & $(\mathrm{Cl})$ \\
\hline Register-recorded denominator & \multicolumn{2}{|l|}{2222 live births } & \multicolumn{2}{|l|}{1839 live births } & \multicolumn{2}{|l|}{6711 live births } & & \\
\hline \multicolumn{9}{|l|}{ All modes of birth combined } \\
\hline Observer prevalence \% & \multicolumn{2}{|l|}{$2582(89.3)$} & \multicolumn{2}{|l|}{$2257(97.9)$} & \multicolumn{2}{|l|}{$7112(99.4)$} & 99.6 & $(88.8,99.9)$ \\
\hline Register-recorded prevalence \% & \multicolumn{2}{|l|}{$2185(98.3)$} & \multicolumn{2}{|l|}{$1796(97.7)$} & \multicolumn{2}{|l|}{$5282(78.7)$} & 93.7 & $(76.4,100.0)$ \\
\hline Not recorded & \multicolumn{2}{|l|}{$13(0.6)$} & \multicolumn{2}{|l|}{$41(2.2)$} & \multicolumn{2}{|l|}{$1394(20.8)$} & 5.4 & $(0.0,23.5)$ \\
\hline Not readable & \multicolumn{2}{|l|}{$0(0)$} & \multicolumn{2}{|l|}{$0(0)$} & \multicolumn{2}{|l|}{$4(0.1)$} & 0.0 & $(0.0,0.1)$ \\
\hline \multicolumn{9}{|c|}{ INCLUDES NOT RECORDED AND NOT READABLE AS NO } \\
\hline$>10$ Cell counts & \multicolumn{2}{|l|}{ No } & \multicolumn{2}{|l|}{ No } & Yes & & & \\
\hline$\%$ agreement & 88.6 & & 96.4 & & 78.7 & & 89.0 & $(76.4,97.1)$ \\
\hline Sensitivity & $* *$ & $* *$ & ** & $* *$ & 79 & $(78,80)$ & 93.8 & $(76.7,100.0)$ \\
\hline Specificity & ** & $* *$ & $* *$ & $* *$ & 25 & $(12.7,41.2)$ & 8.8 & $(0.0,28.0)$ \\
\hline EXCLUDES NOT RECORDED AND N & READABLE & & & & & & & \\
\hline$>10$ Cell counts & No & & No & & No & & & \\
\hline$\%$ agreement & 88.6 & & 96.4 & & 98.9 & & 95.5 & $(87.7,99.5)$ \\
\hline Sensitivity & $* *$ & $* *$ & $* *$ & $* *$ & $* *$ & $* *$ & $* *$ & ** \\
\hline Specificity & $* *$ & $* *$ & $* *$ & $* *$ & $* *$ & $* *$ & $* *$ & $* *$ \\
\hline Vaginal births & & & & & & & & \\
\hline Observer prevalence \% & $731(96.3)$ & & $1290(96.5)$ & & $6075(99.4)$ & & 97.7 & $(94.4,99.6)$ \\
\hline Register-recorded prevalence \% & $547(97.9)$ & & $1073(97.6)$ & & $4963(84.3)$ & & 94.5 & $(82.2,99.9)$ \\
\hline Not recorded & $7(1.3)$ & & $25(2.3)$ & & $894(15.2)$ & & 4.9 & $(0.0,17.1)$ \\
\hline Not readable & $0(0)$ & & $0(0)$ & & $3(0.1)$ & & 0.0 & $(0.0,0.1)$ \\
\hline INCLUDES NOT RECORDED AND NC & READABLE AS N & & & & & & & \\
\hline$>10$ Cell counts & No & & No & & No & & & \\
\hline$\%$ agreement & 94.4 & & 95.4 & & 83.9 & & 91.9 & $(82.1,98.0)$ \\
\hline Sensitivity & $* *$ & $* *$ & $* *$ & $* *$ & $* *$ & $* *$ & $* *$ & ** \\
\hline Specificity & $* *$ & ** & ** & $* *$ & $* *$ & $* *$ & $* *$ & $* *$ \\
\hline EXCLUDES NOT RECORDED AND N & READABLE & & & & & & & \\
\hline$>10$ Cell counts & No & & No & & No & & & \\
\hline$\%$ agreement & 94.4 & & 95.4 & & 98.9 & & 96.6 & $(92.5,99.1)$ \\
\hline Sensitivity & ** & $* *$ & $* *$ & $* *$ & $* *$ & $* *$ & $* *$ & ** \\
\hline Specificity & $* *$ & ** & ** & $* *$ & ** & $* *$ & $* *$ & $* *$ \\
\hline Caesarean births & & & & & & & & \\
\hline Observer prevalence $\%$ & $1850(86.8)$ & & 967 (99.8) & & $1037(99.2)$ & & 97.1 & $(85.6,100.0)$ \\
\hline Register-recorded prevalence $\%$ & $1638(98.5)$ & & $723(97.7)$ & & $318(39)$ & & 85.5 & $(41.5,100.0)$ \\
\hline Not recorded & $6(0.4)$ & & $16(2.2)$ & & $495(60.7)$ & & 12.9 & $(0.0,58.9)$ \\
\hline Not readable & $0(0)$ & & $0(0)$ & & $1(0.1)$ & & 0.0 & $(0.0,0.1)$ \\
\hline INCLUDES NOT RECORDED AND NC & READABLE AS N & & & & & & & \\
\hline$>10$ Cell Counts & No & & No & & No & & & \\
\hline$\%$ agreement & 86.6 & & ** & & 40.2 & & 79.5 & $(43.2,99.3)$ \\
\hline Sensitivity & ** & $* *$ & $* *$ & $* *$ & $* *$ & $* *$ & $* *$ & $* *$ \\
\hline Specificity & $* *$ & $* *$ & $* *$ & $* *$ & $* *$ & $* *$ & $* *$ & $* *$ \\
\hline
\end{tabular}


Table 3 Individual-level validation of register recording for Chlorhexidine cord-application, EN-BIRTH study $(n=6711)$ (Continued)

\begin{tabular}{|c|c|c|c|c|c|c|c|c|}
\hline & \multicolumn{2}{|c|}{$\begin{array}{l}\text { Azimpur (BD) } \\
\text { Tertiary } \\
\end{array}$} & \multicolumn{2}{|c|}{$\begin{array}{l}\text { Kushtia (BD) } \\
\text { District } \\
\end{array}$} & \multicolumn{2}{|c|}{$\begin{array}{l}\text { Pokhara (NP) } \\
\text { Regional }\end{array}$} & \multicolumn{2}{|c|}{$\begin{array}{l}\text { Pooled } \\
\text { (Random effects) }\end{array}$} \\
\hline & $\mathrm{N}(\%)$ & $(\mathrm{Cl})$ & $\mathrm{N}(\%)$ & $(\mathrm{Cl})$ & $\mathrm{N}(\%)$ & $(\mathrm{Cl})$ & $\mathrm{N}(\%)$ & $(\mathrm{Cl})$ \\
\hline \multicolumn{9}{|c|}{ EXCLUDES NOT RECORDED AND NOT READABLE } \\
\hline$>10$ Cell counts & No & & No & & No & & & \\
\hline$\%$ agreement & 86.6 & & $* *$ & & 99.1 & & 95.7 & $(85.5,100.0)$ \\
\hline Sensitivity & ** & $* *$ & $* *$ & $* *$ & $* *$ & ** & $* *$ & ** \\
\hline Specificity & $* *$ & $* *$ & $* *$ & $* *$ & $* *$ & $* *$ & $* *$ & ** \\
\hline
\end{tabular}

$n=12,379$ observed live births, $n=10,772$ live births with register records

** $=$ result suppressed due to 10 or fewer count per column of two-by-two table

$7.1 \%$ Chlorhexidine solution applied to the umbilicus

in Bangladesh used the same register design and instructions; however, they did not perform equally. This may be related to different implementation strategies, as Azimpur BD staff received more detailed training and ongoing support during register rollout.

To date, validation research for tracking of cord care practices has focused on population-based survey platforms with no published evaluation regarding routine facilitybased measurement systems. This is a major gap, given as many as 20 countries have a national policy for CHX that includes facilities, and demonstrates the need for inclusion of CHX as part of the WHO policy portal [22]. To our knowledge, EN-BIRTH is the first study to assess validity of CHX measurement from routine registers. Register design was found to be an important factor in the accuracy of register-recorded coverage in this study, as registers with specific columns outperforming non-specific columns. However, the specific column in Azimpur BD was ticked when $\mathrm{CHX}$ was not given and demonstrates the need for consistent implementation, as well as design.

The increasing proportion of caesarean section births worldwide has important implications for both care and measurement. In one hospital in our study, women who had caesarean underestimated CHX coverage by $75 \%$. In the other two sites there was very little difference between vaginal and caesarean births. Newborns may be cared for separately from their mothers after surgery, and caesarean birth may exacerbate communication gaps, especially if the woman had a general anaesthetic or was unwell following surgery.

Interestingly, the high coverage and timely application of $\mathrm{CHX}$ is in marked contrast to low coverage for breastfeeding, where we found early initiation in the first hour after birth to be just $10.9 \%$ across all five EN-BIRTH study sites [39]. Immediate newborn care is part of essential newborn care and includes a number of practices such as delayed cord clamping, breastfeeding, and skin-to-skin contact, which are needed in the first few minutes after birth. Pre-discharge interventions such as eye care, vitamin $\mathrm{K}$, newborn assessment, cord care and immunisations are required; all should be implemented with a focus on zero separation of women and their newborns [15, 39].

The immediate newborn care practice with the strongest evidence base is early initiation of breastfeeding, with high impact for reducing newborn morbidity and mortality and contributing to health gains for the

\begin{tabular}{|c|c|c|c|c|}
\hline & & BD - Azimpur & BD - Kushtia & NP - Pokhara \\
\hline & & Tertiary & District & Regional \\
\hline \multicolumn{2}{|c|}{ Chlorhexidine application to umbilical cord } & \multicolumn{2}{|c|}{\begin{tabular}{|l|} 
EmONC Register- Revised design \\
\end{tabular}} & \\
\hline Register design & & \multicolumn{2}{|c|}{ Specific column } & Non-specific column \\
\hline & \multirow{2}{*}{ Column Heading } & \multirow{2}{*}{\multicolumn{2}{|c|}{\begin{tabular}{|c|}
$7.1 \%$ Chlorohexidine used on the \\
umbilical cord (yes $/ \mathrm{no}$ )
\end{tabular}}} & \\
\hline & & & & \\
\hline & \multirow{2}{*}{ Column Completed in Practice as } & \multicolumn{2}{|c|}{ Tick for yes, blank for no } & $\mathrm{CHX}$ \\
\hline & & \multicolumn{2}{|c|}{$\begin{array}{l}\text { (clear instruction) } \\
\end{array}$} & \\
\hline Completeness & Data element recorded in register & not possible & not possible & not possible \\
\hline \multicolumn{5}{|l|}{ External Consistency } \\
\hline Indicator: & Observed coverage $\%$ & $89.30 \%$ & $97.90 \%$ & $99.40 \%$ \\
\hline Indicator: & Measured coverage - register recorded $\%$ & $98.30 \%$ & $97.70 \%$ & $78.70 \%$ \\
\hline \multirow{2}{*}{ Measurement gap: } & Register recorded and observed & $9.00 \%$ & $0.20 \%$ & $20.70 \%$ \\
\hline & & over-estimate & under-estimate & under-estimate \\
\hline
\end{tabular}

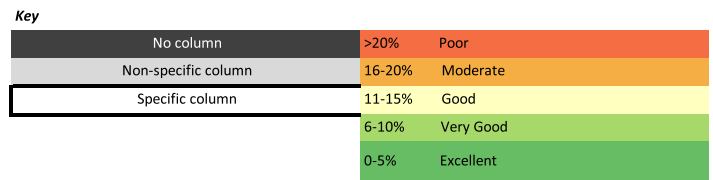

Fig. 4 Facility register design and completion approaches for Chlorhexidine application by site, EN-BIRTH study ( $n=12,379)$. $n=12,379$ observed live births, $n=10,772$ register extracted live births. BD: Bangladesh; NP: Nepal. 7.1\% Chlorhexidine solution applied to the umbilicus. In Bangladesh, the registers were revised to a standardised national EmONC register (Additional file 3), neither original facility register had any column for CHX documentation. Completeness calculations were "not possible" for Bangladesh registers as in this design, left blank also meant that the intervention/ practice was not done. Reference: Cut-off ranges adapted from WHO Data Quality Review, Module 2 "Desk review of data quality" [36] 


\begin{tabular}{|c|c|c|c|c|c|c|}
\hline \multirow{3}{*}{$\begin{array}{l}\text { Chlorhexidine application to } \\
\text { umbilical cord }\end{array}$} & \multirow{3}{*}{ Ratio } & BD - Azimpur & BD - Kushtia & NP - Pokhara & \multirow{3}{*}{ All sites pooled (Random Effects) } & \multirow{3}{*}{$95 \% \mathrm{Cl}$} \\
\hline & & Tertiary & District & Regional & & \\
\hline & & Revised register & Revised register & & & \\
\hline \multirow{2}{*}{ All modes of birth combined } & Survey: Observed & 0.01 & 0.38 & 0.09 & 0.12 & $0.00-0.35$ \\
\hline & Register: Observed & 1.1 & 0.99 & 0.79 & 0.94 & $0.86-1.00$ \\
\hline & & & & & & \\
\hline \multirow{2}{*}{ Vaginal births } & Survey: Observed & 0.01 & 0.46 & 0.09 & 0.14 & $0.00-0.42$ \\
\hline & Register: Observed & 1 & 1.01 & 0.85 & 0.97 & $0.87-1.00$ \\
\hline & & & & & & \\
\hline \multirow{2}{*}{ Caesarean births } & Survey: Observed & 0.01 & 0.05 & 0.06 & 0.08 & $0.00-0.28$ \\
\hline & Register: Observed & 1.13 & 0.98 & 0.4 & 0.88 & $0.40-1.00$ \\
\hline
\end{tabular}

\begin{tabular}{|llll}
$<0.80$ & OR & $>1.20$ & Poor \\
0.80 to 0.84 & OR & 1.16 to 1.20 & Moderate \\
\hline 0.85 to 0.89 & OR & 1.11 to 1.15 & Good \\
\hline 0.90 to 0.94 & OR & 1.06 to 1.10 & Very Good \\
\hline 0.95 to 0.99 & OR & 1.00 to 1.05 & Excellent \\
\hline
\end{tabular}

Fig. 5 Heat map of validity ratios for chlorhexidine cord application, EN-BIRTH study. BD: Bangladesh; NP: Nepal. Using cut off ranges adapted from WHO Data Quality Review, Module 2 "Desk review of data quality" [36]. Survey-reported to observed and register-recorded to observed. Observation $n=12,379$ live births, register-recorded $n=10,002$ live births and exit survey-reported $n=11,827$ women with live births. 7.1\% Chlorhexidine solution applied to the umbilicus

woman [40-42]. CHX application does not yet have strong evidence regarding facility-based application or for requiring application within minutes. Under time pressure, health workers might prioritise more easily achieved simple tasks, such as CHX application, over potentially time-consuming practices like assisting a mother and baby to breastfeed. Other possibilities of why $\mathrm{CHX}$ was prioritised at our study sites might include location of the CHX product (which is only available on the labour ward, rather than postnatal wards) or short admission stays where staff take the opportunity immediately. There are important research questions around the sequencing for immediate and essential newborn care practices to optimise mortality impact, especially with increasing time pressures on the few midwives and other health care professionals.

\section{Strengths and limitations}

Strengths of this study include direct observation as the gold standard, data collection by trained providers using a custom-built tablet application with timestamping, the large sample size and the multi-country, multi-site contexts.

In terms of limitations, we note that validation results are based on CEmONC hospitals, which might not be generalisable to lower levels of care or for women who give birth at home or in private facilities. The presence of researchers could have influenced how health workers completed routine registers (Hawthorne effect) [43]; however, assessment of pre- and during study register data quality is published separately and shows very little difference over time [35].

Our survey questions were aligned to the current DHS optional survey module questions regarding applications to the umbilical cord. However, for EN-BIRTH, we asked women at exit interviews with a short recall period, rather than 2-5 years later, as is usual practice in population-based surveys. Hence, our results could overestimate the validity of measurement for these survey questions, since women may be more likely to accurately report care in this shorter time interval (very soon after birth). Conversely, many women reported "don't know" and it is possible that for home births they may have known more about what was done to their newborn's cord.

\section{Research to improve measurement}

Assessment for impact of CHX in facility settings is ongoing, with results from a trial in Uganda expected soon [20]. For countries that already have a policy of facility-based CHX cord application, further implementation research to explore how register design, filling and use can improve data quality is required. Such research should include assessment of health worker training and support. In addition to assessment of data flow and data quality for this indicator's inclusion in national routine HMIS, evidence of feasibility and cost effectiveness are also required [34]. For home births in high mortality contexts, validation of survey questions regarding women's report of CHX application on the day of birth and afterwards is necessary. These studies could also explore use of visual prompts as used by DHS, such as a picture of the commodity packaging most commonly used in that context.

\section{Conclusions}

Routine register data performed better than exit surveyreport for measurement of $\mathrm{CHX}$ coverage in hospitals. 


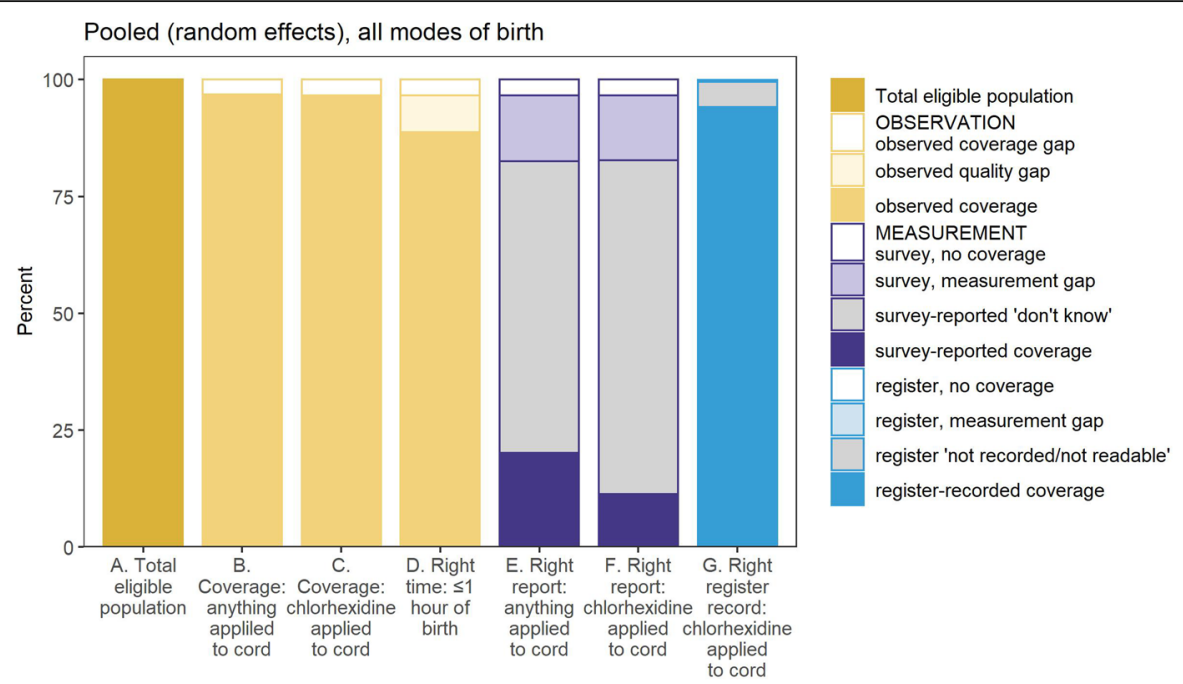

All modes of birth
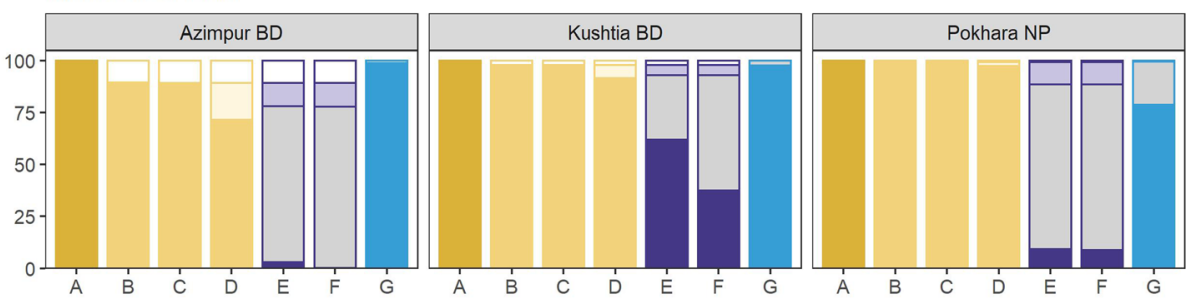

Vaginal birth
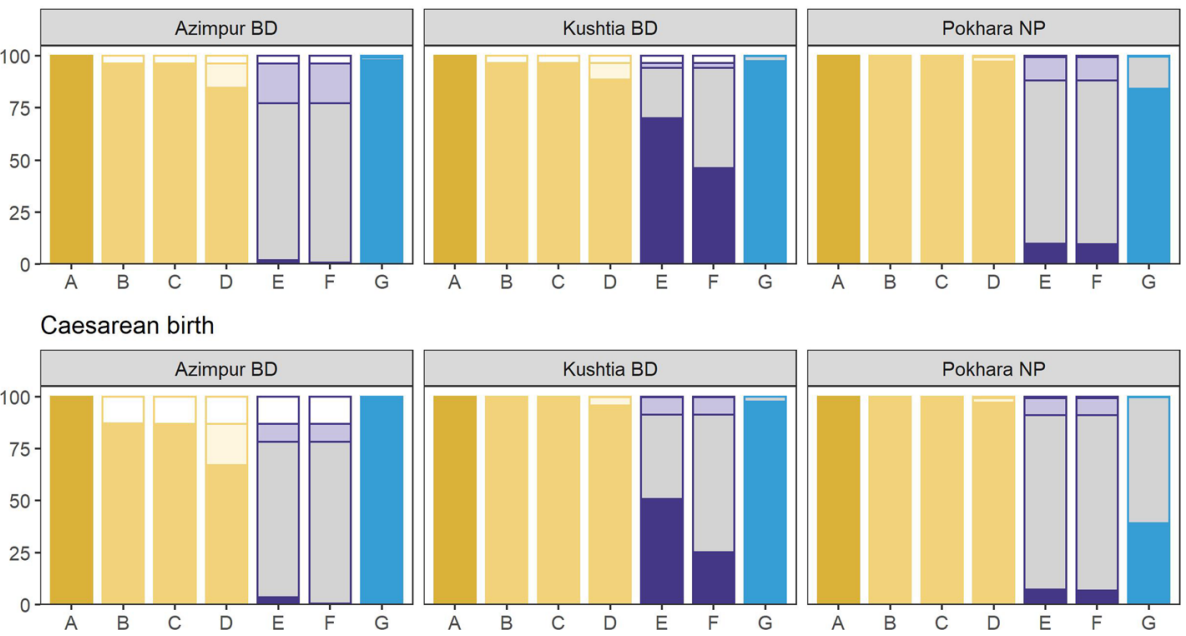

Fig. 6 Gap analysis for Chlorhexidine cord application coverage and quality, EN-BIRTH study $(n=12,379)$. Register-records $n=11,002$ live births, and exit survey-report $n=11,827$ women with live births. 'Right time' $<1 \mathrm{~h}$ was used here as the observation period is only during admission to labour and delivery wards. The current WHO recommendations advise that Chlorhexidine application should be completed within the first week of life [6]. 7.1\% Chlorhexidine solution applied to the umbilicus

Routine registers are a promising source of data where there is a national policy for facility-based CHX application. Further research should assess the opportunity costs in time for health workers to record, as well as utility of the data if coverage is already extremely high. Attention to home births is essential to ensure the poorest and most at-risk families are not omitted from coverage measurement.

\section{Supplementary Information}

The online version contains supplementary material available at https://doi. org/10.1186/s12884-020-03338-4.

Additional file 1. Chlorhexidine question wording compared with DHS/ MICS. DHS: Demographic and Health Surveys; MICS: Multiple Indicator Cluster Surveys.

Additional file 2. EN-BIRTH cord care survey questionnaire used to collect information about cord care and Chlorhexidine cord cleansing. 
Additional file 3. EN-BIRTH study data collection dates by site and time elapsed between birth and exit survey.

Additional file 4. Ethical approval of local institutional review boards for EN-BIRTH study.

Additional file 5. STROBE statement.

Additional file 6. Individual-level validation in exit-survey report of umbilical cord care practices, EN-BIRTH study $(n=12,379)$.

Additional file 7. Exit-survey reported health-worker communication of Chlorhexidine application, EN-BIRTH study ( $n=11,639$ live births),

Additional file 8. Validation register-recorded umbilical cord care practices, EN-BIRTH study $(n=10,772)$.

Additional file 9. Descriptive data for observer-assessed, registerrecorded, and survey-reported Chlorhexidine cord application, EN-BIRTH study ( $n=12,379$ live births).

\section{Abbreviations}

BD: Bangladesh; CEmONC: Comprehensive Emergency Obstetric and Newborn Care; CHX: 7.1\% Chlorhexidine application to the umbilical cord; CIFF: Children's Investment Fund Foundation; DHS: The Demographic and Health Surveys Program; EN-BIRTH: Every Newborn-Birth Indicators Research Tracking in Hospitals study; HMIS: Health Management Information System; icddr,b: International Centre for Diarrhoeal Disease Research, Bangladesh; LSHTM: London School of Hygiene \& Tropical Medicine; MCHTI: Maternal and Child Health Training Institute, Azimpur, Bangladesh; MICS: Multiple Indicator Cluster Survey; NP: Nepal; PRISM: Performance of Routine Information System Management; UNICEF: United Nations International Children's Emergency Fund; WHO: World Health Organization

\section{Acknowledgements}

Firstly, and most importantly, we thank the women, their families, the health workers and data collectors. We credit the inspiration of the late Godfrey Mbaruku. We thank Claudia DaSilva, Veronica Ulaya, Mohammad Raisul Islam, Sudip Karki and Rabina Sarki for their administrative support and Sabrina Jabeen, Goutom Banik, Md. Shahidul Alam, Tamatun Islam Tanha and Md. Mohsiur Rahman for support during data collectors training.

We acknowledge the following groups for their guidance and support: National Advisory Groups:

Bangladesh: Mohammod Shahidullah, Khaleda Islam, Md Jahurul Islam. Nepal: Naresh P. KC, Parashu Ram Shrestha.

Tanzania: Muhammad Bakari Kambi, Georgina Msemo, Asia Hussein, Talhiya

Yahya, Claud Kumalija, Eliudi Eiakimu, Mary Azayo, Mary Drake, Honest Kimaro.

\section{EN-BIRTH validation collaborative group:}

Bangladesh: Md. Ayub Ali, Bilkish Biswas, Rajib Haider, Md. Abu Hasanuzzaman, Md. Amir Hossain, Ishrat Jahan, Rowshan Hosne Jahan, Jasmin Khan, M A Mannan, Tapas Mazumder, Md. Hafizur Rahman, Md. Ziaul Haque Shaikh, Aysha Siddika, Taslima Akter Sumi, Md. Taqbir Us Samad Talha. Tanzania: Evelyne Assenga, Claudia Hanson, Edward Kija, Rodrick Kisenge, Karim Manji, Fatuma Manzi, Namala Mkopi, Mwifadhi Mrisho, Andrea Pembe. Nepal: Jagat Jeevan Ghimire, Rejina Gurung, Elisha Joshi, Avinash K. Sunny, Naresh P. KC, Nisha Rana, Shree Krishna Shrestha, Dela Singh, Parashu Ram Shrestha, Nishant Thakur.

LSHTM: Hannah Blencowe, Sarah G Moxon.

EN-BIRTH Expert Advisory Group: Agbessi Amouzou, Tariq Azim, Debra Jackson, Theopista John Kabuteni, Matthews Mathai, Jean-Pierre Monet, Allisyn C. Moran, Pavani K. Ram, Barbara Rawlins, Jennifer Requejo, Johan Ivar Sæbø, Florina Serbanescu, Lara Vaz.

We are also very grateful to fellow researchers who peer-reviewed this paper.

\section{About this supplement}

This article has been published as part of BMC Pregnancy and Childbirth Volume 21 Supplement 1, 2021: Every Newborn BIRTH multi-country validation study: informing measurement of coverage and quality of maternal and newborn care. The full contents of the supplement are available online at https://bmcpregnancychildbirth.biomedcentral.com/articles/ supplements/volume-21-supplement-1.

\section{Authors' contributions}

The EN-BIRTH study was conceived by JEL, who acquired the funding and led the overall design with support from HR. Each of the three country research teams input to design of data collection tools and review processes, data collection and quality management with technical coordination from HR, GRGL, and DB. The icddr,b team (notably AER, TT, TH, QSR, SA and SBZ) led the development of the software application, data dashboards and database development with VG and the LSHTM team. IHI (notably DS) coordinated work on barriers and enablers for data collection and use, working closely with LTD. QSR was the main lead for data management working closely with $\mathrm{OB}, \mathrm{KS}$ and LTD. For this paper, SBZ, ABS and HR led the analyses and first draft of manuscript working closely with JEL and SEA. All authors (AKC, KP, SA, NT, QSR, NS, $R G, T T, A E R, P S C, B R, L T D)$ revised the manuscript and gave final approval of the version to be published and agree to be accountable for the work. The ENBIRTH study group authors made contributions to the conception, design, data collection or analysis or interpretation of data. This paper is published with permission from the Directors of Ifakara Health Institute, Muhimbili University of Health and Allied Sciences, icddr,b and Golden Community. The author's views are their own, and not necessarily from any of the institutions they represent. EN-BIRTH Study Group

Bangladesh: Qazi Sadeq-ur Rahman, Ahmed Ehsanur Rahman, Tazeen Tahsina, Sojib Bin Zaman, Shafiqul Ameen, Tanvir Hossain, Abu Bakkar Siddique, Aniqa Tasnim Hossain, Tapas Mazumder, Jasmin Khan, Taqbir Us Samad Talha, Rajib Haider, Md. Hafizur Rahman, Anisuddin Ahmed, Shams Arifeen. Nepal: Omkar Basnet, Avinash K Sunny, Nishant Thakur, Regina Jurung, Anjani Kumar Jha, Bijay Jha, Ram Chandra Bastola, Rajendra Paudel, Asmita Paudel, Ashish KC. Tanzania: Nahya Salim, Donat Shamba, Josephine Shabani, Kizito Shirima, Menna Narcis Tarimo, Godfrey Mbaruku (deceased), Honorati Masanja. LSHTM: Louise T Day, Harriet Ruysen, Kimberly Peven, Vladimir Sergeevich Gordeev, Georgia R Gore-Langton, Dorothy Boggs, Stefanie Kong, Angela Baschieri, Simon Cousens, Joy E Lawn.

\section{Funding}

The Children's Investment Fund Foundation (CIFF) are the main funder of the EN-BIRTH Study and funding is administered via The London School of Hygiene \& Tropical Medicine. The Swedish Research Council specifically funded the Nepal site through Lifeline Nepal and Golden Community. We acknowledge the core funders for all the partner institutions. Publication of this manuscript has been funded by CIFF. CIFF attended the study design workshop but had no role in data collection, analysis, data interpretation, report writing or decision to submit for publication. The corresponding author had full access to study data and final responsibility for publication submission decision.

\section{Availability of data and materials}

The datasets generated during and/or analysed during the current study are available on LSHTM Data Compass repository, https://datacompass.lshtm.ac. uk/955/.

\section{Ethics approval and consent to participate}

This study was granted ethical approval by institutional review boards in all operating counties in addition to the London School of Hygiene \& Tropical Medicine (Additional file 4).

Voluntary informed written consent was obtained from all observed participants, their families for newborns, and respondents for the qualitative interviews. Participants were assured of anonymity and confidentiality. All women were provided with a description of the study procedures in their preferred language at admission, and offered the right to refuse, or withdraw consent at any time during the study. Facility staff were identified before data collection began and no health worker refused to be observed whilst providing care. EN-BIRTH is study number 4833, registered at https://www. researchregistry.com

\section{Consent for publication}

Not applicable.

\section{Competing interests}

The authors declare that they have no competing interests. 


\section{Author details}

Maternal and Child Health Division, International Centre for Diarrhoeal Disease Research, Bangladesh (icddr,b), 68 Shahid Tajuddin Ahmed Sarani, Mohakhali, Dhaka, Bangladesh. ${ }^{2}$ The Maternal, Adolescent, Reproductive, \& Child, Health (MARCH) Centre, London School of Hygiene \& Tropical Medicine, London, UK. ${ }^{3}$ Department of Women's and Children's Health, Uppsala University, Uppsala, Sweden. ${ }^{4}$ Florence Nightingale Faculty of Nursing, Midwifery \& Palliative Care, King's College London, London, UK. ${ }^{5}$ Research Division, Golden Community, Lalitpur, Nepal. ${ }^{6}$ Department of Paediatrics and Child Health, Muhimbili University of Health and Allied Sciences, Dar es Salaam, Tanzania. ${ }^{7}$ Department of Health Systems, Impact Evaluation and Policy, Ifakara Health Institute, Dar es Salaam, Tanzania. ${ }^{8}$ PATH, Seattle, WA, USA. ${ }^{9}$ Maternal and Child Survival Program, jhpiego, Baltimore, MD, USA.

\section{Published: 26 March 2021}

\section{References}

1. Blencowe $\mathrm{H}$, Cousens $\mathrm{S}$. Addressing the challenge of neonatal mortality. Tropical Med Int Health. 2013;18(3):303-12.

2. UNICEF. The state of the World's children 2019. Children, food and nutrition: growing well in a changing world. New York: UNICEF; 2019. [https://www. unicef.org/reports/state-of-worlds-children-2019]. Accessed 29 Sep 2020.

3. Liu L, Johnson HL, Cousens S, Perin J, Scott S, Lawn JE, Rudan I, Campbell H, Cibulskis R, Li M. Global, regional, and national causes of child mortality: an updated systematic analysis for 2010 with time trends since 2000. Lancet. 2012;379(9832):2151-61.

4. Moran AC, Kerber K, Sitrin D, Guenther T, Morrissey CS, Newby H, Fishel J, Yoder PS, Hill Z, Lawn JE. Measuring coverage in MNCH: indicators for global tracking of newborn care. PLoS Med. 2013;10(5):e1001415.

5. Mullany LC, Darmstadt GL, Tielsch JM. Role of antimicrobial applications to the umbilical cord in neonates to prevent bacterial colonization and infection: a review of the evidence. Pediatr Infect Dis J. 2003;22(11):996.

6. World Health Organization: Recommendations on Postnatal care of the mother and newborn. 2014 WHO library cataloguing- Oct 2013. [https:/www. who.int/maternal_child_adolescent/documents/postnatal-carerecommendations/en/. Accessed 29 Sep 2020.

7. PATH: From research to use: saving newborn lives with chlorhexidine for umbilical cord care. 2017. [https://path.azureedge.net/media/documents/ DT_CHX_story_rpt.pdf]. Accessed 29 Sep 2020.

8. El Arifeen S, Mullany LC, Shah R, Mannan I, Rahman SM, Talukder MRR, Begum N, Al-Kabir A, Darmstadt GL, Santosham M. The effect of cord cleansing with chlorhexidine on neonatal mortality in rural Bangladesh: a community-based, cluster-randomised trial. Lancet. 2012;379(9820):1022-8.

9. Mullany LC, Darmstadt GL, Khatry SK, Katz J, LeClerq SC, Shrestha S, Adhikari $\mathrm{R}$, Tielsch JM. Topical applications of chlorhexidine to the umbilical cord for prevention of omphalitis and neonatal mortality in southern Nepal: a community-based, cluster-randomised trial. Lancet. 2006;367(9514):910-8.

10. McClure EM, Goldenberg RL, Brandes N, Darmstadt GL, Wright LL, Group CW. The use of chlorhexidine to reduce maternal and neonatal mortality and morbidity in low-resource settings. Int J Gynecol Obstet. 2007;97(2):89-94.

11. Imdad A, Bautista RMM, Senen KAA, Uy MEV, Mantaring JB III, Bhutta ZA. Umbilical cord antiseptics for preventing sepsis and death among newborns. Cochrane Database Syst Rev. 2013;(5):CD008635.

12. Soofi S, Cousens S, Imdad A, Bhutto N, Ali N, Bhutta ZA. Topical application of chlorhexidine to neonatal umbilical cords for prevention of omphalitis and neonatal mortality in a rural district of Pakistan: a community-based, cluster-randomised trial. Lancet. 2012;379(9820):1029-36.

13. Mullany LC, Shah R, El Arifeen S, Mannan I, Winch PJ, Hill A, Darmstadt GL, Baqui AH. Chlorhexidine cleansing of the umbilical cord and separation time: a cluster-randomized trial. Pediatrics. 2013;131(4):708-15.

14. Mullany LC, Darmstadt GL, Khatry SK, LeClerq SC, Katz J, Tielsch JM. Impact of umbilical cord cleansing with $4.0 \%$ chlorhexidine on time to cord separation among newborns in southern Nepal: a cluster-randomized, community-based trial. Pediatrics. 2006;118(5):1864-71.

15. World Health Organization. WHO Recommendations on newborn health: guidelines approved by the WHO guidelines review committee. Geneva: WHO; 2017. [https://apps.who.int/iris/handle/10665/259269]. Accessed 29 Sep 2020 .
16. Sazawal S, Dhingra U, Ali SM, Dutta A, Deb S, Ame SM, Mkasha MH, Yadav A, Black RE. Efficacy of chlorhexidine application to umbilical cord on neonatal mortality in Pemba, Tanzania: a community-based randomised controlled trial. Lancet Glob Health. 2016;4(11):e837-44.

17. Semrau KE, Herlihy J, Grogan C, Musokotwane K, Yeboah-Antwi K, Mbewe R, Banda B, Mpamba C, Hamomba F, Pilingana P. Effectiveness of 4\% chlorhexidine umbilical cord care on neonatal mortality in Southern Province, Zambia (ZamCAT): a cluster-randomised controlled trial. Lancet Glob Health. 2016;4(11):e827-36.

18. Okomo U, Akpalu EN, Le Doare K, Roca A, Cousens S, Jarde A, Sharland M, Kampmann B, Lawn JE. Aetiology of invasive bacterial infection and antimicrobial resistance in neonates in sub-Saharan Africa: a systematic review and meta-analysis in line with the STROBE-NI reporting guidelines. Lancet Infect Dis. 2019;19(11):1219-34.

19. Mwananyanda L, Pierre C, Mwansa J, Cowden C, Localio AR, Kapasa ML, Machona S, Musyani CL, Chilufya MM, Munanjala G. Preventing bloodstream infections and death in Zambian neonates: impact of a low-cost infection control bundle. Clin Infect Dis. 2019;69(8):1360-7.

20. Nankabirwa V, Tylleskär T, Tumuhamye J, Tumwine JK, Ndeezi G, Martines JC, Sommerfelt H. Efficacy of umbilical cord cleansing with a single application of $4 \%$ chlorhexidine for the prevention of newborn infections in Uganda: study protocol for a randomized controlled trial. Trials. 2017;18(1):322.

21. Mullany LC, El Arifeen S, Khatry SK, Katz J, Shah R, Baqui AH, Tielsch JM. Impact of chlorhexidine cord cleansing on mortality, omphalitis, and cord separation time among facility-born babies in Nepal and Bangladesh. Pediatr Infect Dis J. 2017:36(10):1011.

22. Global chlorhexidine scale-up tracker: location of use [https:/www. healthynewbornnetwork.org/chlorhexidine-location/. Accessed 28 Sep 2020.

23. Multiple indicator cluster surveys (MICS)6 tools [http://mics.unicef.org/ tools\#survey-design]. Accessed 29 Sep 2020.

24. Demographic and Health Surverys (DHS) Model questionnaire - phase 7 [https://dhsprogram.com/publications/publication-dhsq7-dhsquestionnaires-and-manuals.cfm]. Accessed 29 Sep 2020.

25. Bhattacharya AA, Allen E, Umar N, Usman AU, Felix H, Audu A, Schellenberg $J R$, Marchant T. Monitoring childbirth care in primary health facilities: a validity study in Gombe State, northeastern Nigeria. J Glob Health. 2019;9(2).

26. Hancioglu A, Arnold F. Measuring coverage in MNCH: tracking progress in health for women and children using DHS and MICS household surveys. PLoS Med. 2013;10(5):e1001391.

27. Blanc AK, Diaz C, McCarthy KJ, Berdichevsky K. Measuring progress in maternal and newborn health care in Mexico: validating indicators of health system contact and quality of care. BMC Pregnancy Childbirth. 2016;16(1):255.

28. Blanc AK, Warren C, McCarthy KJ, Kimani J, Ndwiga C, RamaRao S. Assessing the validity of indicators of the quality of maternal and newborn health in Kenya. J Glob Health. 2016;6(1): 010405.

29. McCarthy K, Blanc AK, Warren CE, Kimani J, Mdawida B, Ndwidga C. Can surveys of women accurately track indicators of maternal and newborn care? A validity and reliability study in Kenya. J Glob Health. 2016;6(2):020502.

30. Stanton CK, Rawlins B, Drake M, dos Anjos M, Cantor D, Chongo L, Chavane $\mathrm{L}$, da Luz VM, Ricca J. Measuring coverage in MNCH: testing the validity of women's self-report of key maternal and newborn health interventions during the peripartum period in Mozambique. PLoS One. 2013;8(5):e60694.

31. Strachan M, Drake M, Rawlins B, Dwivedi V, Levine B, Ly M, Ishola G: Strengthening health management information systems for maternal and child health: documenting MCHIP's Contributions. Baltimore: Jhpiego , 17:2014.

32. Jolivet RR, Moran AC, O'Connor M, Chou D, Bhardwaj N, Newby H, Requejo J, Schaaf M, Say L, Langer A. Ending preventable maternal mortality: phase II of a multi-step process to develop a monitoring framework, 2016-2030. BMC Pregnancy Childbirth. 2018;18(1):258.

33. World Health Organization, UNICEF. Every newborn; an action plan to end preventable deaths. Geneva: WHO; 2014. [https://www.who.int/maternal_ child_adolescent/newborns/every-newborn/en/]. Accessed 29 Sep 2020.

34. Day LT, Ruysen H, Gordeev VS, Gore-Langton GR, Boggs D, Cousens S, Moxon SG, Blencowe H, Baschieri A, Rahman AE, et al. "Every newbornBIRTH" protocol: observational study validating indicators for coverage and quality of maternal and newborn health care in Bangladesh, Nepal and Tanzania. J Glob Health. 2019:9(1):010902.

35. Day LT, Rahman QS, Rahman A, Salim N, KC A, Ruysen H, Tahsina T, Masanja $\mathrm{H}$, Basnet $\mathrm{O}$, Gordeev V, et al. Assessment of the validity of the measurement of newborn and maternal health-care coverage in hospitals 
(EN-BIRTH): a mixed-methods observational study. Lancet Glob Health. https://doi.org/10.1016/S2214-109X(20)30504-0.

36. World Health Organization. Data quality review: a toolkit for facility data quality assessment. Module 2: desk review of data quality. Geneva: World Health Organisation; 2017. [https://apps.who.int/iris/handle/10665/259225]. Accessed 28 Sep 2020.

37. Shamba D, Day LT, Zaman SB, Khan J, Talha T, Rahman M, Kayastha A, Thakur $N$, Tarimo M, Singh N et al: Barriers and enablers to routine register data collection for newborns and mothers: EN-BIRTH multi-country validation study. BMC Pregnancy Childbirth. 2021; https:/doi.org/10.1186/s12884-020-03517-3.

38. Performance of Routine Information System Management (PRISM) [https:// www.measureevaluation.org/our-work/routine-health-information-systems/ performance-of-routine-information-system-management-prism.]. Accessed 29 Sep 2020.

39. Tahsina T, Hossain AT, Ruysen H, Rahman AE, Day LT, Peven K, Rahman QS-U, Khan J, Shabani J, KC A, et al. Immediate newborn care and breastfeeding: EN-BIRTH multi-country validation study. BMC Pregnancy Childbirth. 2021; https://doi.org/10.1186/s1 2884-020-03421-w.

40. Khan J, Vesel L, Bahl R, Martines JC. Timing of breastfeeding initiation and exclusivity of breastfeeding during the first month of life: effects on neonatal mortality and morbidity - a systematic review and meta-analysis. Matern Child Health J. 2015;19(3):468-79.

41. NEOVITA Study Group. Timing of initiation, patterns of breastfeeding, and infant survival: prospective analysis of pooled data from three randomised trials. Lancet Glob Health. 2016;4(4):e266-75.

42. Debes AK, Kohli A, Walker N, Edmond K, Mullany LC. Time to initiation of breastfeeding and neonatal mortality and morbidity: a systematic review. BMC Public Health. 2013;13(3):S19.

43. Campbell JP, Maxey VA, Watson WA. Hawthorne effect: implications for prehospital research. Ann Emerg Med. 1995;26(5):590-4.

\section{Publisher's Note}

Springer Nature remains neutral with regard to jurisdictional claims in published maps and institutional affiliations.

Ready to submit your research? Choose BMC and benefit from:

- fast, convenient online submission

- thorough peer review by experienced researchers in your field

- rapid publication on acceptance

- support for research data, including large and complex data types

- gold Open Access which fosters wider collaboration and increased citations

- maximum visibility for your research: over $100 \mathrm{M}$ website views per year

At $\mathrm{BMC}$, research is always in progress.

Learn more biomedcentral.com/submissions 